\title{
Impact ionization coefficients in strained InGaAs/InAlAs multiquantum wells
}

\author{
A. L. Gutierrez-Aitken and P. K. Bhattacharya \\ Solid State Electronics Laboratory, Department of Electrical Engineering and Computer Science, \\ The University of Michigan, Ann Arbor, Michigan 48109-2122
}

(Received 3 August 1992; accepted for publication 22 January 1993)

We have measured electron and hole impact ionization coefficients in biaxially strained $\mathrm{In}_{x} \mathrm{Ga}_{1-x} \mathrm{As} / \mathrm{In}_{y} \mathrm{Al}_{1-y} \mathrm{As}(0.44<x<0.62,0.44<y<0.62)$ multiquantum wells for the first time. It is seen that $\beta / \alpha$ is enhanced due to strain-induced changes in band gap, band offsets, and bandstructure for tensile strain in the well and compressive strain in the barrier. The results have been interpreted by considering band-to-band impact ionization and band-edge discontinuity impact ionization processes.

\section{INTRODUCTION}

Recently, there has been significant interest in avalanche photodiodes (APD) where the avalanche region consists of a superlattice (SL) or multiquantum well (MQW) structure. As McIntyre ${ }^{1,2}$ demonstrated, a large difference in the ionization rates for electrons $(\alpha)$ and holes $(\beta)$ is needed for a low-noise APD. The MQW APD was first proposed by Chin et al. ${ }^{3}$ and since then experimental evidence of enhancement of the impact ionization rates ratio has been reported..$^{4-8}$ This effect is attributed to the difference in the conduction and valence-band edge discontinuities ${ }^{6}$ and to differences in scattering rates and confinement of electrons and holes. ${ }^{8}$ As discussed by Smith et al. ${ }^{9}$ and Chuang ct $a l^{10}$ and demonstrated by Capasso et al. ${ }^{11}$ and $\mathrm{Yu}$ et al. ${ }^{4}$ in a MQW structure there are two different impact ionization processes: band-to-band impact ionization (BBII) and band-edge discontinuity impact ionization (BEDII). In this work, biaxial strain has been used to alter the band gaps and band offsets in InGaAs/InAlAs MQW structures, and the corresponding effects on the two processes have been measured.

\section{DEVICE FABRICATION}

The devices used in this study were $p^{+}-i$ (MQW) $-n^{+}$ diodes prepared by molecular-beam epitaxy (MBE). The $i$ layer is an undoped $\operatorname{In}_{x} \mathrm{Ga}_{1-x} \mathrm{As} / \mathrm{In}_{y} \mathrm{Al} 1_{1-y} \mathrm{As}(0.44<x$ $<0.62,0.44<y<0.62)$ MQW avalanche region sandwiched by Be-doped $p$-type and Si-doped $n$-type $\mathrm{In}_{0.53} \mathrm{Ga}_{0.47} \mathrm{As}$ layers grown on a semi-insulating (100) InP substrate. A 10-period $\mathrm{In}_{0.53} \mathrm{Ga}_{0.47} \mathrm{As} / \mathrm{In}_{0.52} \mathrm{Al}_{0.48} \mathrm{As}, 25$ $\AA / 25 \AA, S L$ is first grown on the substrate to minimize the defect density in the active region of the device. The $p$-type $\left(5 \times 10^{18} \mathrm{~cm}^{-3}\right)$ and $n$-type $\left(1 \times 10^{19} \mathrm{~cm}^{-3}\right)$ layers are thick enough $(2 \mu \mathrm{m})$ to absorb all the light at $\lambda=1.55 \mu \mathrm{m}$ and prevent the generation of electron-hole pairs in the $\mathrm{MQW}$ region. The InP substrate is virtually transparent at this wavelength and allowed us to illuminate the back of the samples for pure hole injection from the $n$-InGaAs layer under reverse-bias conditions. The parameters of the MQW in the different samples are listed in Table $I$. In what follows, we will refer to the strain of the MQW region as the strain in the well and not the strain in the barrier, remembering that the signs of the strain tensors are opposite in the two regions. We have designed the MQW region such that the strain in the well is compensated by the strain in the barrier. The individual well and barrier thicknesses are under critical thickness for the strain applied to that layer in order to preserve a pseudomorphic structure. Using the parameters given by Tiwari, ${ }^{12}$ we have calculated the band-edge values at room temperature shown in Table II.

\section{RESULTS AND DISCUSSION}

To inject electrons into the MQW region we generated electron-hole pairs in the $p$-type layer by focusing a $1.55-\mu \mathrm{m}$ laser on the top surface of standard $150-\mu \mathrm{m}$-diam mesa diodes. Similarly, to inject holes into the MQW region we generated electron-hole pairs in the $n$-type layer by focusing the laser on the back through the InP substrate. The forward current-voltage $(I-V)$ characteristics of samples UMV 2061, 2062, and 2071 are shown in Fig. 1. Each curve shows different slopes at low and high voltages, suggesting different conduction mechanisms. The current at low bias is dominated by thermionic emission, whereas the current at high bias is dominated by tunneling. To verify this, we plotted the $\log \left(I / V^{2}\right)$ vs $(1 / V)$ relationship following the Fowler-Nordheim theory. ${ }^{13}$ We find that the slope in the tunneling region (high voltage) for compressive strain in the well is steeper than the slope for tensile strain in the well. This result suggests that the band offsets for compressive strain are larger than the band offsets for tensile strain, which agrees with the estimated values of $\Delta E_{c}$ and $\Delta E_{v}$ in Table II. Furthermore, the thermionic

TABLE I. Parameters of the MQW avalanche region.

\begin{tabular}{|c|c|c|c|c|c|}
\hline Sample & $\begin{array}{l}\text { Composition } \\
\text { of MQW } \\
\text { avalanche layer }\end{array}$ & $\begin{array}{l}\text { Number } \\
\text { of } \\
\text { periods }\end{array}$ & $\begin{array}{c}\text { Total } \\
\text { thickness } \\
(\mu \mathrm{m})\end{array}$ & $\begin{array}{c}\text { Well } \\
\text { width } \\
(\AA)\end{array}$ & $\begin{array}{c}\text { Barrier } \\
\text { width } \\
\text { (苂) }\end{array}$ \\
\hline UMV 1966 & $\mathrm{In}_{0,51} \mathrm{Gra} a_{0.49} \mathrm{As} / \mathrm{In}_{0,58} \mathrm{Al}_{10,4,2} \mathrm{As}$ & 150 & 1.50 & 70 & 30 \\
\hline UMV 1967 & $\mathrm{In}_{0,53} \mathrm{Ga}_{0.47} \mathrm{As} / \mathrm{In}_{0.52} \mathrm{Al}_{0.4 \times} \mathrm{As}$ & 150 & 1.50 & 70 & 30 \\
\hline UMV 2061 & $\mathrm{In}_{0,53} \mathrm{Ga}_{0,47} \mathrm{As} / \mathrm{In}_{0,52} \mathrm{Al}_{0,43} \mathrm{As}$ & 37 & 1.48 & 200 & 200 \\
\hline UMV 2062 & $\mathrm{In}_{0.44} \mathrm{Ga}_{0.56} \mathrm{As} / \mathrm{In}_{0.62} \mathrm{Al}_{0.38} \mathrm{As}$ & 37 & 1.48 & 200 & 200 \\
\hline UMV 2071 & $\mathrm{In}_{0,62} \mathrm{Ga}_{0,38} \mathrm{As} / \mathrm{In}_{0.44} \mathrm{Al}_{0.50} \mathrm{As}$ & 37 & 1.48 & 200 & 200 \\
\hline
\end{tabular}


TABLE II. Strain and band-edge values of the MQW region.

\begin{tabular}{lcccccc}
\hline & Strain in & Well & Barrier \\
the well & $\begin{array}{c}\text { band gap } \\
(\mathrm{eV})\end{array}$ & $\begin{array}{c}\text { band gap } \\
(\mathrm{eV})\end{array}$ & $\begin{array}{c}\Delta E_{g} \\
(\mathrm{eV})\end{array}$ & $\begin{array}{c}\Delta E_{c} \\
\text { Sample }\end{array}$ & $\begin{array}{c}\mathrm{eV}) \\
(\mathrm{eV})\end{array}$ \\
\hline UMV 1966 & Tensile (-0.2\%) & $\mathbf{0 . 7 8}$ & 1.27 & 0.49 & 0.32 & 0.17 \\
UMV 1967 & Lattice-matched & 0.75 & 1.43 & 0.68 & 0.48 & 0.20 \\
UMV 2061 & Lattice-matched & 0.75 & 1.43 & 0.68 & 0.48 & 0.20 \\
UMV 2062 & Tensile (-0.6\%) & 0.83 & 1.19 & 0.36 & 0.21 & 0.15 \\
UMV 2071 & Compressive $(+0.6 \%)$ & 0.65 & 1.62 & 0.97 & 0.70 & 0.27 \\
\hline
\end{tabular}

emission current is proportional to $e^{q \phi_{B^{\prime}} k T}$, where $\phi_{B}$ is the barrier height. In Fig. 2, we see that the value of the current for compressive strain is lower than the value for tensile strain, implying that the barrier is larger for the compressive strain case than for the tensile strain case. This result also agrees with the estimated band-gap offset values for the strained samples shown in Table II.

The photocurrent $\left(I_{\text {total }}-I_{\text {dark }}\right)$-voltage profiles for electron and hole injection, and the dark current-voltage of samples UMV 2061, 2062, and 2071 are shown in Fig. 2. For sample UMV 2062, the photocurrent at a multiplication factor $(M)$ of unity is well defined. For samples UMV 2061 and 2071 the photocurrent at $M=1$ is not well defined. To be able to estimate $\beta / \alpha$ in these two samples, we calibrated the laser power to have practically the same value of photocurrent for electron and hole injection. In addition, using the formulas given by Stillman et al. ${ }^{14}$ for $\alpha$ and $\beta$ for a $p-i-n$ diode, the ratio $\beta / \alpha$ is to some extent less dependent of the photocurrent chosen as a reference. On the contrary, the absolute values of $\alpha$ and $\beta$ are dependent on the chosen reference photocurrent.

Using the aforementioned formulas we calculated $\alpha$ and $\beta$ for samples UMV 2061, 2062, and 2071 assuming a linear variation of the electric field in the avalanche region. The data are shown in Fig. 3(a). The data for the latticematched case agree with the results reported by Kagawa et al. ${ }^{5}$ at a field of $2 \times 10^{5} \mathrm{~V} / \mathrm{cm}$ and those reported by Allam ct al.,$^{15}$ considering the fact that the structure used in Ref. 15 had a larger well thickness. The effect of com-

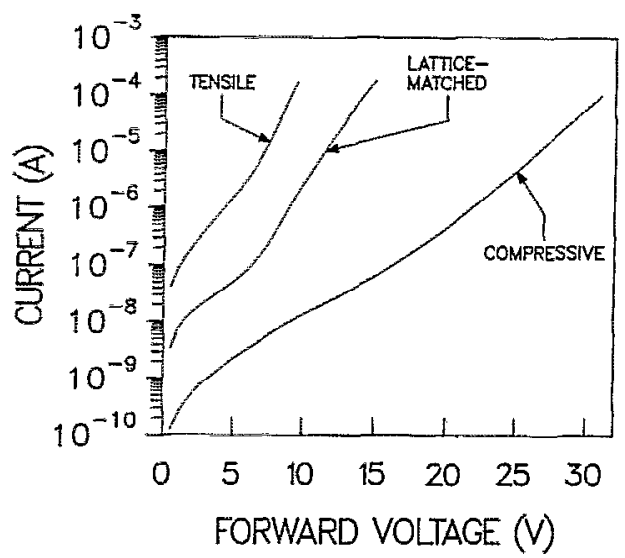

FIG. 1. Forward $I-V$ characteristics of samples UMV 2061 (latticematched), 2062 (tensile), and 2071 (compressive).

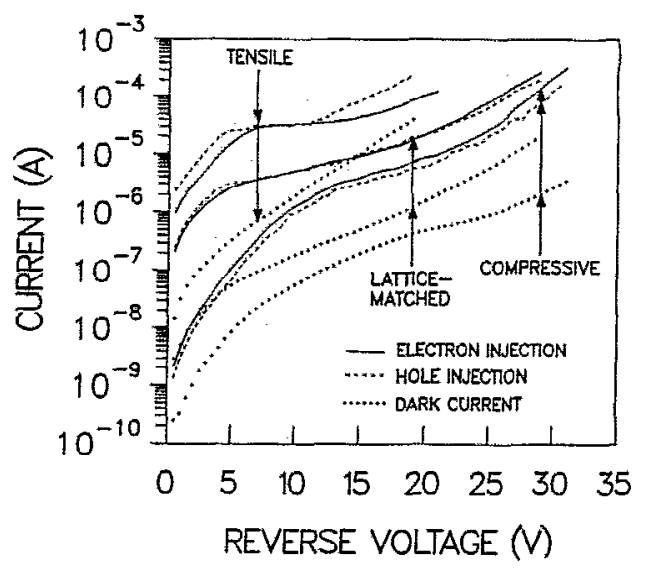

FIG. 2. Electron injection photocurrent, hole injection photocurrent, and dark current of samples UMV 2061 (lattice-matched), 2062 (tensile), and 2071 (compressive).

pressive strain in the well on the magnitude of $\alpha$ and $\beta$, compared to the lattice-matched case, is small despite the decrease of the well band gap from 0.75 to $0.65 \mathrm{eV}$. But, as Singh $^{16}$ has pointed out, the decrease of the hole mass due

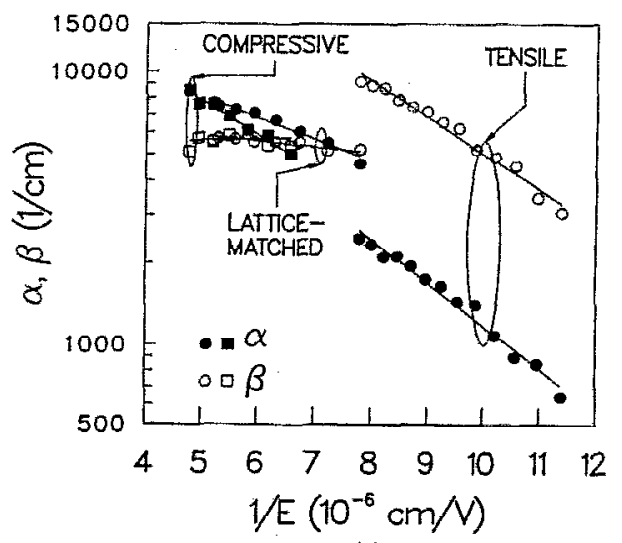

(d)

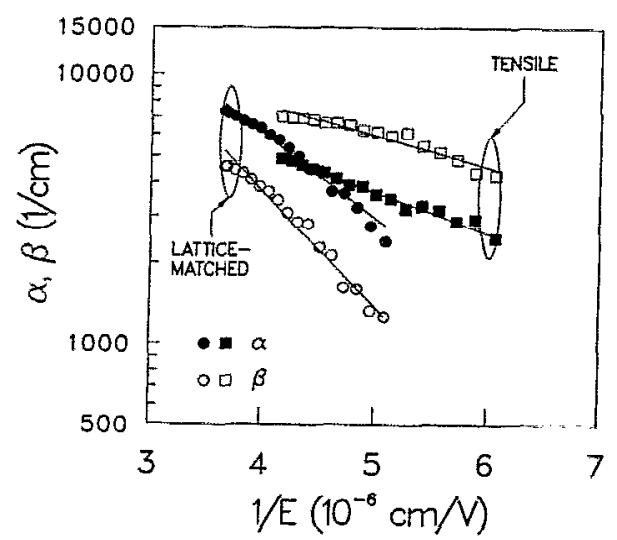

(b)

FIG. 3. (a) Measured electron ( $\alpha$ ) and hole $(\beta)$ impact ionization coefficients of samples UMV 2061 (lattíce-matched), 2062 (tensile), and 2071 (compressive). (b) Measured electron $(\alpha)$ and hole $(\beta)$ impact ionization coefficients of samples UMV 1966 (tensile) and 1967 (latticematched). 
to compressive strain partially compensates for the decrease in the BBII threshold energy. On the other hand, the results for sample UMV 2062 with tensile strain in the well show an enhancement in $\beta$ and a reduction in $\alpha$. The increase of the band gap in the well from 0.75 to $0.83 \mathrm{eV}$ and the strain-induced changes in the band structure increase the BBII threshold energy. Consequently the BBII rates for both electrons and holes are reduced. However, the decrease in the band-edge discontinuities enhances the BEDII rates, particularly for holes, since $\Delta E_{v}<\Delta E_{c}$. As a net result, $\beta / \alpha$ is enhanced. As indicated by Capasso et al. ${ }^{11}$ the BEDII process occurs at lower electric fields than the BBII process. We do observe this behavior in sample UMV 2062 since multiplication starts at $\sim 8 \times 10^{4}$ $\mathrm{V} / \mathrm{cm}$, which agrees very well with the electric field value for BEDII given by $\mathrm{Yu}$ et al. ${ }^{4}$ The impact ionization coefficients for samples UMV 1966 and UMV 1967 [Fig. 3(b)] also show an enhancement of $\beta / \alpha$ for the sample with tensile strain in the well. This suggests that even with narrower wells and barriers, BEDII is enhanced over BBII due to tensile strain in the well.

These results are promising particularly for applications in low-noise avalanche photodiodes. However, further study is required since many processes influence the values and the ratio of impact ionization coefficients in MQW structures and different processes dominate in different material systems. For example, Kagawa et al. ${ }^{17}$ pointed out that in $\mathrm{GaAs} / \mathrm{Al}_{x} \mathrm{Ga}_{1-x}$ As the electron ionization rate is enhanced when the AlGaAs of the barrier is a direct transition type and it is reduced when the AlGaAs barriers become an indirect transition type. This result also agrees with the result reported by Susa et al. ${ }^{18}$ who did not observe any electron impact ionization enhancement for $\mathrm{GaAs} / \mathrm{Al}_{x} \mathrm{Ga}_{1-x}$ As MQW with an indirect barrier ( $x$ $=0.53$ ). In addition, Bhattacharya et al ${ }^{8}$ demonstrated that the hole confinement and scattering in the wells play a dominant role in altering the ionization coefficient ratio in the GaAs/AlGaAs material system. For InGaAs/InAlAs MQWs contradictory impact ionization results have been published. Kagawa et al. ${ }^{5}$ reported a $\alpha / \beta \sim 20$ for an InGaAs/InAlAs structure with $400 \AA / 200 \AA$ well and barrier widths, respectively. On the other hand, Capasso et al. ${ }^{11}$ reported a $\beta / \alpha \sim 20$ for a similar structure. It seems that growth conditions, material quality, and interface quality are very important in determining the value of the impact ionization coefficients.

\section{CONCLUSION}

We have measured the effect of strain on impact ionization coefficients in strained InGaAs/InAlAs MQWs for the first time. The measurements reported here were done in samples grown in the same MBE machine under the same growth conditions and within a short period of time. Our data suggest that BEDII is enhanced over BBII due to changes in band gap, band offsets, and strain-induced band structure. The net result is an enhancement of $\beta / \alpha$ for a MQW structure with tensile strain in the well and compressive strain in the barrier.

\section{ACKNOWLEDGMENTS}

The authors wish to thank W-Q. Li and H-C. Sun for growing the diode structures and L. Davis for his help during the measurements. This work is supported by the U.S. Army Research Office under the URI program Grant No. DAAL03-92-G-0109.

${ }^{1}$ R. J. McIntyre, IEEE Trans. Electron. Devices ED-13, 164 (1966).

${ }^{2}$ R. J. McIntyre, IEEE Trans. Electron. Devices ED-19, 703 (1972).

${ }^{3}$ R. Chin, N. Holonyak, G. E. Stillman, J. Y. Tang, and K. Hess, Electron. Lett. 16, 467 (1980).

${ }^{4}$ Y-J. Yu, G. Bosman, and P. K. Bhattacharya, Appl. Phys. Lett. 51, 1433 (1987).

${ }^{5}$ T. Kagawa, Y. Kawamura, H. Asai, M. Naganuma, and O. Mikami, Appl. Phys. Lett. 55, 993 (1989).

${ }^{6}$ F. Capasso, W. T. Tsang, A. L. Hulclinson, and G. F. Williams, Appl. Phys. Lett. 40, 38 (1982).

${ }^{7}$ F-Y. Juang, U. Das, Y. Nashimoto, and P. K. Bhattacharya, Appl. Phys. Lett. 47, 972 (1985).

${ }^{8}$ P. K. Bhattacharya, Y. Zebda, and J. Singh, Appl. Phys. Lett. 58, 2791 (1991).

${ }_{9}^{9}$ J. S. Smith, L. C. Chiu, S. Margalit, A. Yariv, and A. Y. Cho, J. Vac. Sci, Technol. B 1, 376 (1983).

${ }^{10}$ S. L. Chuang and K. Hess, J. Appl. Phys. 59, 2885 (1986).

${ }^{11}$ F. Capasso, J. Allam, A. Y. Cho, K. Mohammed, R. J. Malik, A. L. Hutchinson, and D. Sivco, Appl. Phys. Lett. 48, 1294 (1986).

${ }^{12}$ S. Tiwari, Compound Semiconductor Devices (Academic, San Diego, 1992), p. 407.

${ }^{13}$ S. M. Sze, Physics of Semiconductor Devices, 2nd ed. (Wiley, New York, 1981), p. 403.

${ }^{14} \mathrm{G}$. E. Stillman and C. M. Wolfe, in Semiconductors and Semimetals, edited by R. K. Willardson and A. C. Beer (Academic, New York, 1977), Vol. 12, pp. 291-393.

${ }^{15} \mathrm{~J}$. Allam, F. Capasso, K. Alavi, and Y. Cho, in Proceedings of the 13th International Symposium on GaAs and Related Compounds, edited by W. T. Lindley (Institute of Physics, Bristol, 1986), p. 405.

${ }^{16} \mathrm{~J}$. Singh, Semicond. Sci. Technol. 7, B509 (1992).

${ }^{17}$ T. Kagawa, H. Iwamura, and O. Mikami, Appl. Phys. Lett. 54, 33 (1989).

I8 N. Susa and H. Okamoto, Jpn. J. Appl. Phys. 23, 317 (1984). 